University of Nebraska - Lincoln

DigitalCommons@University of Nebraska - Lincoln

Faculty Publications from the Harold W. Manter Laboratory of Parasitology

12-1999

\title{
Fatal Cysticercosis by Taenia crassiceps (Cyclophyllidea: Taeniidae) in a Presumed Immunocompromised Canine Host
}

\author{
Eric P. Hoberg \\ United States Department of Agriculture, ehoberg@ggpl.arsusda.gov \\ William Ebinger
}

James A. Render

Follow this and additional works at: https://digitalcommons.unl.edu/parasitologyfacpubs

Part of the Parasitology Commons

\begin{abstract}
Hoberg, Eric P.; Ebinger, William; and Render, James A., "Fatal Cysticercosis by Taenia crassiceps (Cyclophyllidea: Taeniidae) in a Presumed Immunocompromised Canine Host" (1999). Faculty Publications from the Harold W. Manter Laboratory of Parasitology. 402.

https://digitalcommons.unl.edu/parasitologyfacpubs/402
\end{abstract}

This Article is brought to you for free and open access by the Parasitology, Harold W. Manter Laboratory of at DigitalCommons@University of Nebraska - Lincoln. It has been accepted for inclusion in Faculty Publications from the Harold W. Manter Laboratory of Parasitology by an authorized administrator of DigitalCommons@University of Nebraska - Lincoln. 


\section{Fatal Cysticercosis by Taenia crassiceps (Cyclophyllidea: Taeniidae) in a Presumed Immunocompromised Canine Host}

Eric P. Hoberg, William Ebinger ${ }^{\star}$, and James A. Rendert, United States Department of Agriculture, Agricultural Research Service, Biosystematics and National Parasite Collection Unit, BARC East No. 1180, 10300 Baltimore Avenue, Beltsville, Maryland 20705. *Oakland Animal Hospital, 180 East Second Street, Rochester, Michigan 48307. †Animal Health Diagnostic Laboratory and Department of Veterinary Pathology, College of Veterinary Medicine, Michigan State University, East Lansing, Michigan 48824

ABSTRACT: Cysticercosis in a canine host (Canis familiaris) attributable to the taeniid cestode Taenia crassiceps is reported for the first time in North America. Numerous parent and daughter cysticerci occurred in a massive intrapleural and intraperitoneal infection in an apparently immunocompromised host. The largest cysticerci were ovoid to elongate, 5-9 $\mathrm{mm}$ in maximum length, and armed with $32-34$ rostellar hooks in 2 rows; small hooks measured 114-143 $\mu \mathrm{m}$ long $(\bar{x}=$ $124 \pm 8.2 \mu \mathrm{m})$, and large hooks were $156-180 \mu \mathrm{m}(\bar{x}=163 \pm 7.4$ $\mu \mathrm{m})$. Taenia crassiceps is widespread in boreal North America and, like a number of other taeniids, constitutes a potential risk as a zoonotic parasite. The immunological status of the host may be important in determining the outcome of infections for this and other taeniids in atypical hosts.

Taenia crassiceps (Zeder, 1800) is a commonly occurring tapeworm in the Holarctic and circulates among canids and rodents across northern regions of the United States and Canada (e.g., Leiby and Whittaker, 1966; Freeman et al., 1973; Anderson et al., 1990). Strobilate adults are intestinal parasites that develop in foxes (including Vulpes vulpes L. and Alopex lagopus L.), coyotes (Canis latrans Say), and other canids such as domesticated dogs (Canis familiaris L.), whereas cysticerci generally occur in the musculature, subcutaneous tissues, peritoneal, and pleural cavity of various rodents (Rausch, 1959; Freeman, 1962; Abuladze, 1965; Verster, 1969). We report a remarkable disseminated intraperitoneal, intrapleural, and pulmonary cysticercosis attributable to $T$. crassiceps in a young chocolate Labrador retriever from Columbus, Michigan, treated with immunosuppressive drugs.
A 6-mo-old female dog weighing 53 lbs was examined for bilateral exophthalmos. The ocular condition was thought to have been caused by an immune-mediated extraocular polymyositis. Treatment consisting of prednisolone $(25 \mathrm{mg}$ p.o., twice a day, PO/BID; Ved Co Inc., St. Joseph, Missouri) and Imuran ${ }^{\circledR}$ (25 mg, PO/BID; e.g., Azthioprine, USP; Glaxo-Wellcome, Research Triangle, North Carolina) for 33 days resulted in an improved condition except for a slight anemia with a packed cell volume (PCV) of 31.9\%. Subsequent treatment consisting of prednisolone (20 mg, BID) and Imuran ${ }^{\circledR}(25 \mathrm{mg}$, BID) continued for 5 days; the latter was discontinued when clinical findings included severe ventral abdominal cutaneous bruising, jaundice, and shock with pale mucous membranes and respiratory distress. Clotting time was normal, and PCV was $30 \%$. Serum alkaline phosphatase was 1,963 and the alanine aminotransferase (ALT) was 2,304. Radiographically, the chest and abdomen were unremarkable. A transfusion of $250 \mathrm{ml}$ of canine blood was administered and amoxicilin $(500 \mathrm{mg}$ PO/ BID; Consolidated Pharmaceuticals, Baltimore, Maryland) was given. Eventually, acute hemolytic crisis and dyspnea developed. Prednisolone (5 mg PO/BID) along with amoxicilin were administered until the time of euthanasia, 6 days later. During this time, PCV dropped from 30 to $17 \%$, the white blood cell count (WBC) from 20,760 to 18,700 , ALT from 2,010 to 276, and alkaline phosphatase from 2,548 to 1,806 . Presumed immunosuppression in this host is consistent with high dosages of 

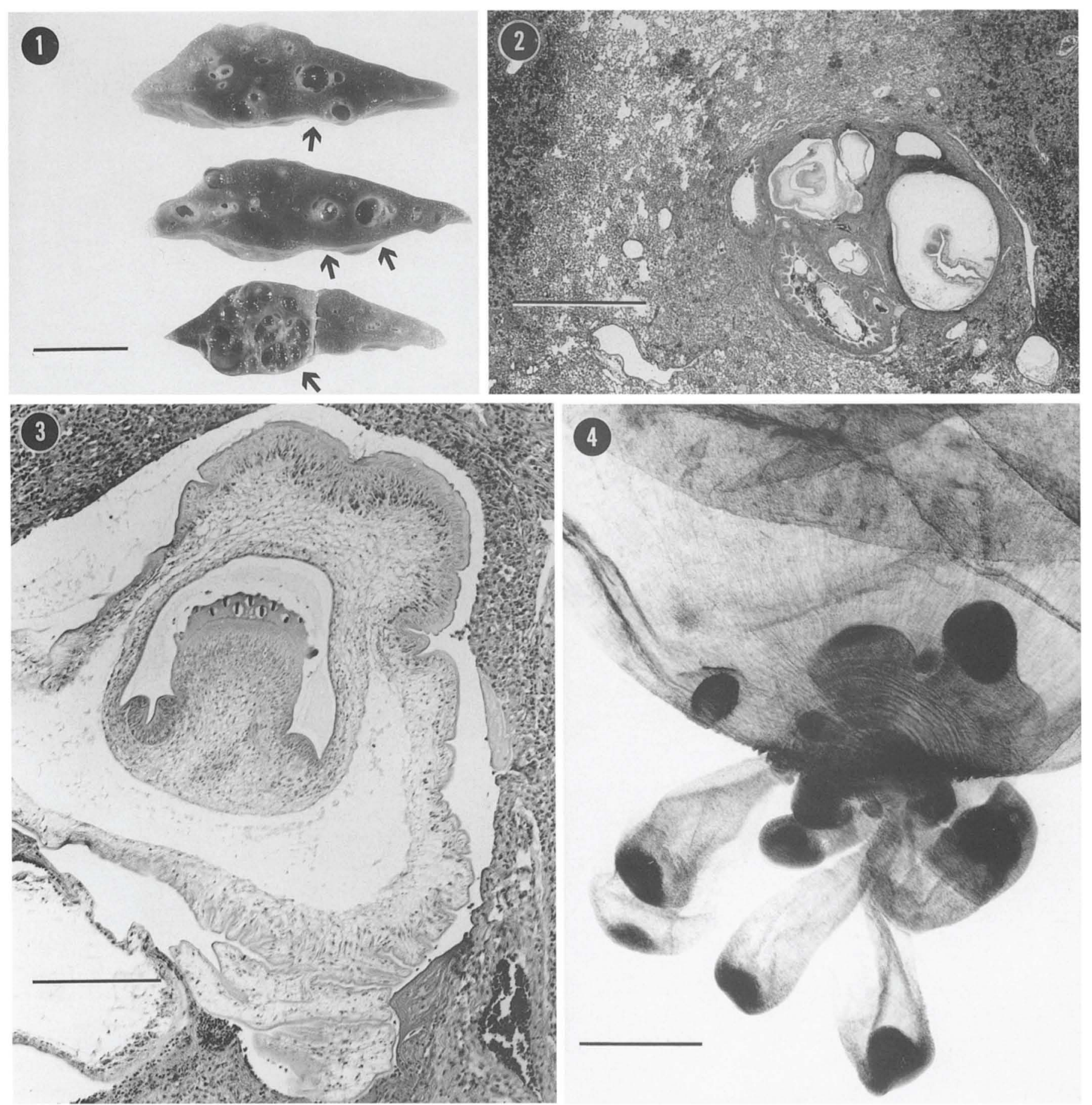

FIGURES 1-4. Cysticercosis by Taenia crassiceps in a canine host. 1. Gross lesions in the lung shown in transverse hand-cut sections; note cavities (arrows) containing numerous cysticerci, demarcated by connective-tissue capsules (scale $=10 \mathrm{~mm}$ ). 2. Cysticerci within cavernous inflammatory lesion surrounded by areas of hemorrhage in the lung of a dog, shown in tissue section stained with H\&E (scale $=1.5 \mathrm{~mm}$ ) 3 . Parent cysticercus fully developed with two rows of rostellar hooks, shown in tissue section from lung (scale $=200 \mu \mathrm{m}$ ). 4. Parent cysticercus showing abscolex end with numerous daughter cysticerci in various stages of development; wholemount stained with Semichon's acetic carmine $($ scale $=400 \mu \mathrm{m})$.

prednisolone and Imuran over a 33-day period and the clinical observations of liver failure and changes in the WBC. At the time of euthanasia the dog was icteric, anemic, weak, panting, and anorexic. Euthanasia was accomplished by administration of Socumb ${ }^{\circledR}$ (pentobarbital sodium at $6 \mathrm{gm} / \mathrm{ml}$; The Butler Company, Columbus, Ohio).
During postmortem, numerous (too abundant to count accurately), ovoid to slightly elongate cysticerci, approximately 5$9 \mathrm{~mm}$ in length for the largest metacestodes, were found free and observed moving within the pleural and peritoneal cavities (Figs. 1,2). The lungs were diffusely edematous and with multiple hemorrhages. Additionally, multiple cavities, each con- 

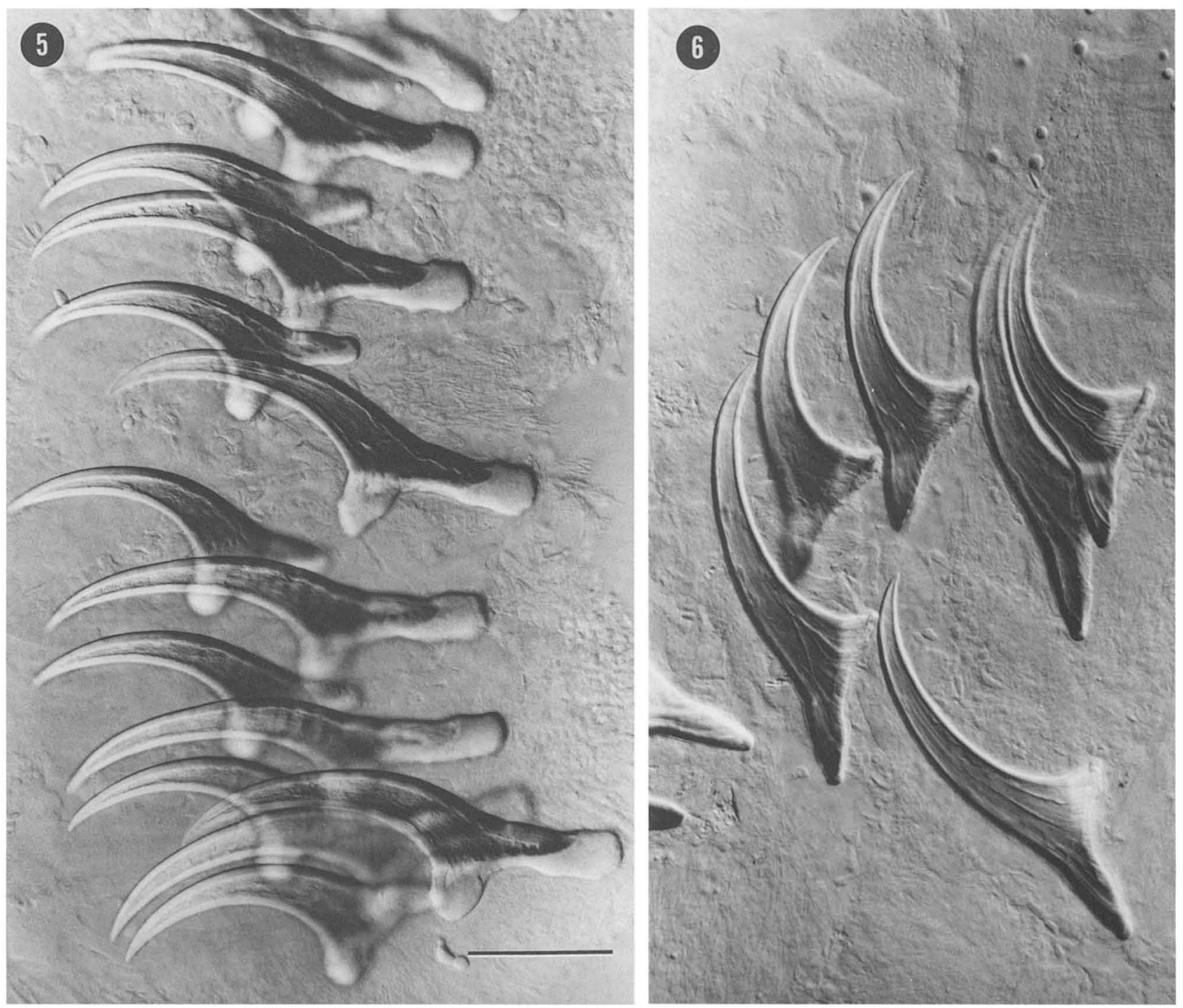

FIGURES 5, 6. Rostellar armature of $T$. crassiceps showing characteristic structure of small and large hooks $(\mathrm{scale}=50 \mu \mathrm{m}) .5$. Parent cysticercus with completely developed hooks. 6. Rostellar armature showing hooks with incomplete development of the handle.

taining 1 cysticercus or multiple cysticerci, were scattered throughout the lungs. Other tissues or organs were not involved, and otherwise appeared unremarkable. Strobilate specimens of cestodes were not present in the small intestine.

Samples of various tissues, including extraocular muscles, and numerous cysticerci were collected and fixed in buffered $10 \%$ formalin. Fixed tissues were trimmed, processed, embedded in paraffin, and sectioned. Tissue sections, 4-5 $\mu \mathrm{m}$ thick, were stained with hematoxylin and eosin (H\&E). Representative metacestodes were stained with Semichon's acetic carmine, dehydrated in ethanol, cleared in xylene, and mounted entire in Canada balsam; hooks from some specimens were mounted separately to allow detailed study of structure.

Histologically, extraocular muscles had extensive infiltration of lymphocytes and plasma cells between myofibers and multifocal necrosis and loss of myofibers. Proteinaceous fluid, blood, and many macrophages were present in alveoli. Metacestodes were present within capsules delimited by fibrous con- nective tissue containing eosinophils, lymphocytes, and plasma cells (Figs. 2, 3).

Cysticerci were morphologically and ontogenetically consistent with $T$. crassiceps. Among 10 specimens collected from the peritoneal cavity and mounted entire, all were ovoid to elongate and 5-9 $\mathrm{mm}$ in maximum length by $3-4 \mathrm{~mm}$ in width; numerous specimens were considerably smaller. Cysticerci exhibited exogenous and endogenous budding at the polar end opposite the invaginated scolex (Fig. 4); development was proliferative. Among 5 scolices, the rostellum was armed with 2 rows of 16-17 small and large hooks (Figs. 5, 6), respectively, for a total of 32-34. Small hooks measured 114-143 $\mu \mathrm{m}$ long ( $\mathrm{n}=35 ; \bar{x}=124 \pm 8.2 \mu \mathrm{m})$, and large hooks were 156-180 $\mu \mathrm{m}(\mathrm{n}=35 ; \bar{x}=163 \pm 7.4 \mu \mathrm{m})$. Representative specimens have been deposited in the U.S. National Parasite Collection, Biosystematics and National Parasite Collection Unit, USDA, Agricultural Research Service, Beltsville, Maryland (USNPC 87835). 
Taenia crassiceps is unique among the taeniids in having a proliferative cysticercus that develops asexually by exogenous budding (Freeman, 1962). Rostellar hooks have a characteristic form, with the blade being markedly longer than the handle (Abuladze, 1965; Verster, 1969). In strobilate specimens in canids and in mature metacestodes in rodents, there are usually 30-36 hooks (occasionally as few as 28), with small hooks measuring 107-155 $\mu \mathrm{m}$ and large hooks $155-200 \mu \mathrm{m}$ in length (Rausch, 1959; Freeman, 1962; Leiby and Whittaker, 1966; Verster, 1969). Chermette et al. (1996) reported 31-34 hooks, measuring 92-153 $\mu \mathrm{m}$ and 145-201 $\mu \mathrm{m}$ for small and large forms, respectively, from cysticerci infecting dogs in France.

Globally, cysticercosis or coenurosis due to species of Taenia Linnaeus, 1758 in companion animals has been reported sporadically, and most infections have been documented in feline hosts (e.g., Kingston et al., 1984; Huss et al., 1994). Reports of cysticercosis other than Taenia solium Linnaeus, 1758 in canine hosts are apparently rare, although dogs serve as definitive hosts for at least 7 species of Taenia (Verster, 1969; Chermette et al., 1993, 1996). In the United States, only cysticerci of $T$. pisiformis (Bloch, 1780) have been reported in dogs (Ivens et al., 1969); the record herein is the first from North America for cysticercosis attributable to $T$. crassiceps in a canine host. In France there have been 3 reported cases of cysticercosis due to $T$. crassiceps in dogs (Chermette et al., 1993, 1996). Among these hosts, 2 had cysticerci in subcutaneous tissues and 1 had a massive peritoneal infection similar to that observed in the current study.

The epizootiology of canine cysticercosis is incompletely understood. All cases have been in rural situations where foxes and a diversity of rodents are common (Chermette et al., 1996). In Michigan and other boreal regions of the U.S., definitive hosts for $T$. crassiceps would be expected to include red fox, coyote, and dogs, whereas intermediate hosts may be represented by voles and mice (e.g., species of Microtus Schrank and Peromyscus Gloger), squirrels (e.g., species of Tamias Illiger, Sciurus Linnaeus, and Tamiasciurus Trouessart), woodchucks (e.g., Marmota monax (Linnaeus)), and other rodents (see Freeman, 1962). With respect to the current case, the locality is an isolated area of northern Michigan, red foxes and coyotes are known in the local area, and the dog had recently eaten mice that had been caught by resident cats. Other companion animals in the household included 2 domesticated cats that were usually outside the residence.

Exposure to infection for canine hosts may follow several potential routes: (1) via eggs in the environment, (2) autoinfection via eggs from a strobilate and gravid adult, and (3) via ingestion of cysticerci in the intermediate host (Freeman, 1962; Kroeze and Freeman, 1982; Chermette et al., 1993, 1996). Relatively few oncospheres may be expected to result in a massive infection (Freeman, 1962), and there may be up to 13,000 eggs in a typical gravid segment (Miyaji et al., 1990). In the rodent intermediate host, complete development of the scolex requires 35-42 days; budding occurs by 28 days PI, leading to massive infections that result from the cumulative production of cysticerci (Freeman, 1962).

The presence of numerous parent and daughter cysticerci suggests that the dog was infected for at least several months or had initially received a large infective dose. Alternatively, the stage of development for metacestodes and the occurrence of both parent and daughter cysticerci in a young dog may be consistent with an infection acquired following ingestion of an intermediate host.

Previous disease, stress, or medical and surgical procedures leading to an impaired immune system may predispose canines to cysticercosis (Chermette et al., 1993, 1996). Thus, presumed immunosuppression of the dog in the current study, due to administration of prednisolone and Imuran may have been a contributing factor to a massive proliferative infection by $T$. crassiceps; Imuran is typically used as an immunosuppressant (Coppoc, 1988). Immunosuppression of this host is clearly suggested based on continuous treatment for 33 days at the highest recommended dosages for these drugs. The immunological status of the host may be important in determining the outcome of infections for this and other taeniids.

Taenia crassiceps is widespread in boreal North America and, like a number of other taeniids, constitutes a potential risk as a zoonotic parasite (Freeman et al., 1973). Infections by $T$. crassiceps, however, may be particularly serious due to their proliferative nature, in contrast to cysticercosis associated with other species of Taenia. Subcutaneous infections may pose a limited clinical problem in humans, but localization in other organs could result in serious disease (Freeman et al., 1973; Chermette et al., 1996). The recent reports from Europe of proliferative infection by $T$. crassiceps in immunocompromised patients with HIV highlights the potential importance of taeniids as zoonotic parasites (Chermette et al., 1995).

The authors thank Linda Mansfield and Alice Murphy of the Parasitology Laboratory, Animal Health Diagnostic Laboratory, Michigan State University, for their assistance during this study. We also thank Arthur Abrams of the BNPCU, ARS, Beltsville, for some photography.

\section{LITERATURE CITED}

Abuladze, K. I. 1965. Taeniata of animals and man and the diseases caused by them. In Essentials of cestodology 10, K. I. Skrjabin (ed.). Akad Nauk SSSR, Helminthological Laboratory, Moscow. 549 p. [English Translation, 1970, by Israel Program for Scientific Translations, Jerusalem.]

Anderson, W. I., D. W. Scott, W. E. Hornbuckle, J. M. King, and B. C. Tennant. 1990. Taenia crassiceps infection in the woodchuck: A retrospective study of 13 cases. Veterinary Dermatology 1: 8592.

Chermette, R., J. Bussiéras, E. Biétola, H. Moret, M. Mialot, and P.-C. RAYNAL. 1996. Quelques parasitoses canines exceptionnelles en France III-Cysticercose proliférative du chien à Taenia crassiceps: à propos de trois cas. Pratique Médicale and Chirurgicale de l'Animal de Compagnie 31: 125-135.

- J. Marionneau, E. Boyer, C. Roubin, B. Prophette, H. MAIllard, AND B. FABIANI. 1995. Cysticercose envahissante à Taenia crassiceps chez un patient atteint de sida. Bulletin de l'Académie Nationale de Médecine 179: 777-783.

-1, M. Mialot, AND P. C. Raynal. 1993. Subcutaneous Taenia crassiceps cysticercosis in a dog. Journal of the American Veterinary Medical Association 203: 263-265.

Coppoc, G. L. 1988. Chemotherapy of neoplastic diseases. In Veterinary pharmacology and therapeutics, 6th ed., N. H. Booth and L. E. MacDonald (eds.). Iowa State University Press, Ames, Iowa, p. $861-876$.

FREEMAN, R. S. 1962. Studies on the biology of Taenia crassiceps (Zeder, 1800) Rudolphi, 1810 (Cestoda). Canadian Journal of Zoology 40: 969-990.

, A. M. Fallis, M. Shea, A. L. Maberley, and J. Walters. 1973. Intraocular Taenia crassiceps (Cestoda) Part II. The parasite. American Journal of Tropical Medicine and Hygiene 22: 493-495. 
Huss, B. T., M. A. Miller, R. M. Corwin, E. P. Hoberg, and D. F $\rightarrow$ Leiby, P. D., And F. H. Whittaker. 1966. Occurrence of Taenia crasOBRIEN. 1994. Fatal cerebral coenurosis in a cat. Journal of the American Veterinary Medical Association 205: 69-71.

Ivens, V., J. D. Conroy, AND N. D. Levine. 1969. Taenia pisiformis cysticerci in a dog in Illinois. American Journal of Veterinary Research 30: 2017-2020.

Kingston, N., E. S. Williams, R. C. Bergstrom, W. C. Wilson, and R. Miller. 1984. Cerebral coenuriasis in domestic cats in Wyoming and Alaska. Proceedings of the Helminthological Society of Washington 51: 309-314.

Kroeze, W. K., AND Freeman, R. S. 1982. Taenia crassiceps: Fate of cysticerci following ingestion by the mouse. Experimental Parasitology 54: $425-431$. siceps in the conterminous United States. Journal of Parasitology 52: 786.

MiYaJ, S., Y. OKU, M. КамiYa, M. ОкамOTO, M. Оhbayashi, А. UСhIDA, AND R. L. RAUSCH. 1990. Growth of a Japanese isolate of Taenia crassiceps in intermediate and definitive hosts. Parasitology Research 76: 351-354.

Rausch, R. L. 1959. Studies on the helminth fauna of Alaska. XXXV. On the identity of certain cestodes (Taeniidae) from foxes. Proceedings of the Helminthological Society of Washington 26: 125131.

Verster, A. 1969. A taxonomic revision of the genus Taenia Linnaeus, 1758 s. str. Onderstepoort Journal of Veterinary Research 36: 358 . 